\title{
Evidence of silent cerebral embolism in patients with amaurosis fugax
}

\author{
M. J . G. H A R R IS O N A N D J O N M A R S H A L L \\ From the Department of Neurological Studies, The Middlesex Hospital, and Institute of Neurology, \\ The National Hospital, London
}

SUMMARY In 34 patients who presented with attacks of amaurosis fugax with no evidence of cerebral involvement, EEG, angiographic, and regional cerebral blood flow studies were carried out. Six of 23 EEGs, one of 21 angiograms, and five of six regional blood flow studies were thought to provide evidence of silent cerebral embolism. The implications for the management of patients who present with isolated amaurosis fugax are discussed.

Most attacks of transient monocular visual loss in the middle-aged and elderly are thought to be due to retinal microembolism. The evidence rests on the occasional detection of visible retinal embolism during attacks (Fisher 1959), the prevalence of atheroma of the carotid artery bifurcation on angiography (Sandok et al., 1974; Wilson and Ross Russell, 1976), and the therapeutic success of carotid endarterectomy (Bauer et al., 1969; Hooshmand et al., 1974) and antiplatelet drugs (Harrison et al., 1971; Evans, 1973).

Some patients also give a history of episodic cerebral hemisphere ischaemia attributable to microembolism in intracranial branches of the carotid artery. Fisher (1952) stressed the common association of retinal ischaemic attacks and episodes of ischaemia in the ipsilateral cerebral hemisphere in patients with stenosis of the internal carotid artery. If the embolic theory of the cause of attacks of amaurosis fugax is correct some patients with no history of cerebral ischaemia might nonetheless be experiencing cerebral embolism. The purpose of the present study was to seek evidence of this.

\section{Methods}

We studied 34 patients aged between 34 and 75 years (mean 56 years) admitted to the National Hospital, Queen Square or the Middlesex Hospital. In each case the patient presented with a history

Address for reprint requests: Dr M. J. G. Harrison, Department of Neurological Studies, The Middlesex Hospital Medical School, London W1N 8AA.

Accepted 11 January 1977 of transient visual loss in one eye with no history of cerebral ischaemia. In no case was there any neurological deficit on detailed clinical examination.

The investigations which we thought might provide evidence of cerebral involvement were the electroencephalographs (EEG), the carotid angiograms, and regional cerebral blood flow studies.

Twenty-three EEGs available for review were studied without access to the clinical data so the side of the attacks of amaurosis fugax was unknown. Note was made of any asymmetry of alpha rhythm, and of any generalised or lateralised excess of theta or delta activity. All the records had been obtained within eight weeks of an episode of visual loss.

In 21 patients a carotid angiogram was available for study (the other patients had had arch angiograms). The intracranial branches of the internal carotid artery on the side of the affected eye had been outlined in each instance, and the results were reviewed for any evidence of distal branch occlusions that might be considered embolic. In each instance the interval between the last clinical episode and the arteriogram was less than six months but in only a half was it less than one month.

In six patients regional cerebral blood flow measurements had been made using the intracarotid injection of ${ }^{133}$ Xenon (Wilkinson et al., 1969). The distribution of flow in fast and slow clearing tissues was reviewed for evidence of focal abnormalities attributable to ischaemic lesions (Shah et al., 1972). One patient was reported previously as case 2 of Rees et al. (1970). 


\section{Results}

In the 23 cases studied by electroencephalography six records showed a focal or lateralising abnormality. In two this consisted of a pathological reduction of amplitude and abundance of the alpha rhythm on one side, and in another there was a generalised excess of theta activity over one hemisphere. In three patients there was a frontotemporal or sylvian focal theta or delta wave abnormality (Fig. 1). In all six patients the abnormality proved to be on the same side as the affected retina.

Among the 21 angiograms there was one example of an intracranial branch occlusion (occlusion of the posterior temporal branch of the ipsilateral middle cerebral artery) (Fig. 2).

The regional cerebral blood flow (rCBF) study was normal in one patient. In the other five patients in which it was carried out, areas of low flow (more than 3.3 SD below figures for the same detector in a control population) were found in the frontal, temporal, or central areas (Fig. 3).

\section{Discussion}

After ccrebral infarction involving the cerebral cortex, localised EEG abnormalities may consist of loss of normal rhythms with or without associ- ated slow wave foci (Van der Drift, 1972). These abnormalities commonly show a tendency to resolution particularly when the hemiplegia is not persistent. Woolsey and Hambrook (1974) studied 30 patients with transient cercbral ischaemic attacks. Nine showed diffuse or focal slowing of EEG activity thought to reflect residual changes in cerebral function not clinically evident.

In six of 23 patients suffering from isolated attacks of retinal ischaemia in the present study, lateralising abnormalities were found in the EEG on the appropriate sidc. It seems likely that these reflect the effect of silent embolism into the cerebral hemisphere as well as in the eye.

Only one of the angiograms was reported to show a middle cerebral or anterior cerebral branch artery occlusion. In this one case this finding is very strong presumptive evidence of coexistent cerebral embolism without clinical effects. The tendency for such embolic occlusions to clear (Dalal et al., 1965) means that many other examples may have been missed if emboli occurred at about the same time as the retinal attacks since several weeks often elapsed before angiography was carried out.

Rees et al. (1970) showed that areas of low cerebral blood flow might be found many weeks after a cerebral transient ischaemic attack even though the clinical accompaniments had been

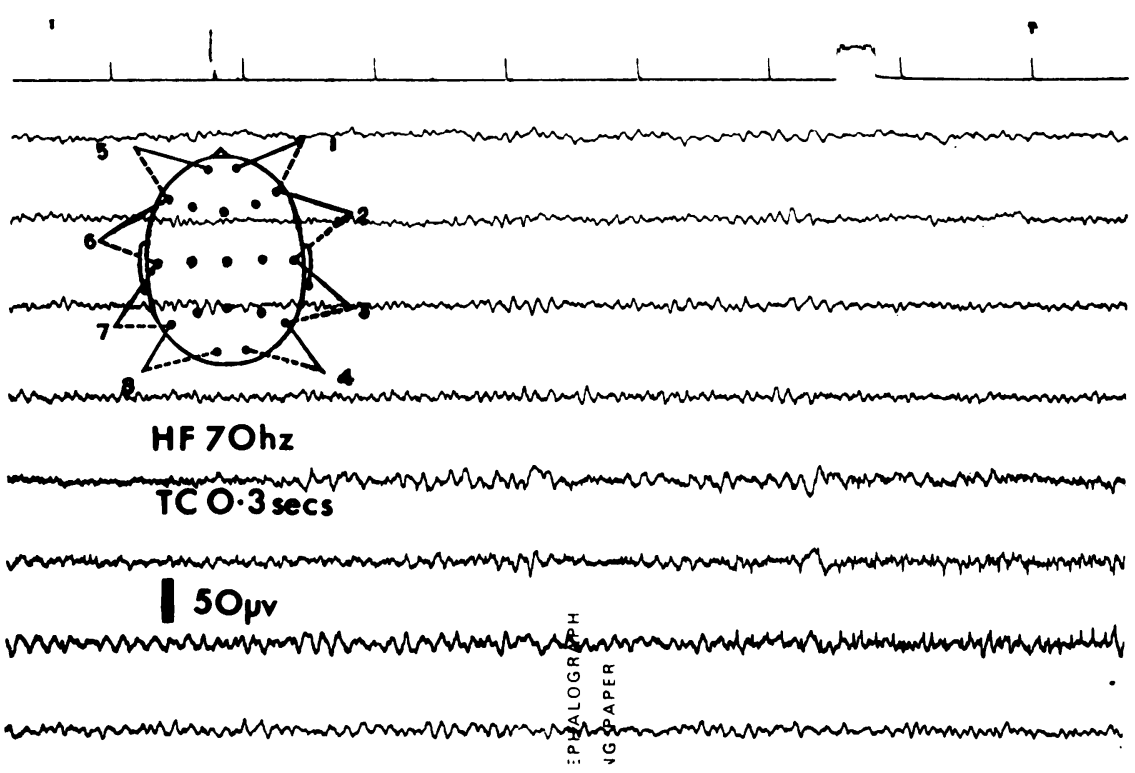

Fig. 1 EEG three weeks after an episode of amaurosis fugax in the left eye, showing a left frontotemporal abnormality. 10-20 system of electrode placement. Siemens Elema mingograf (Patient FW). 


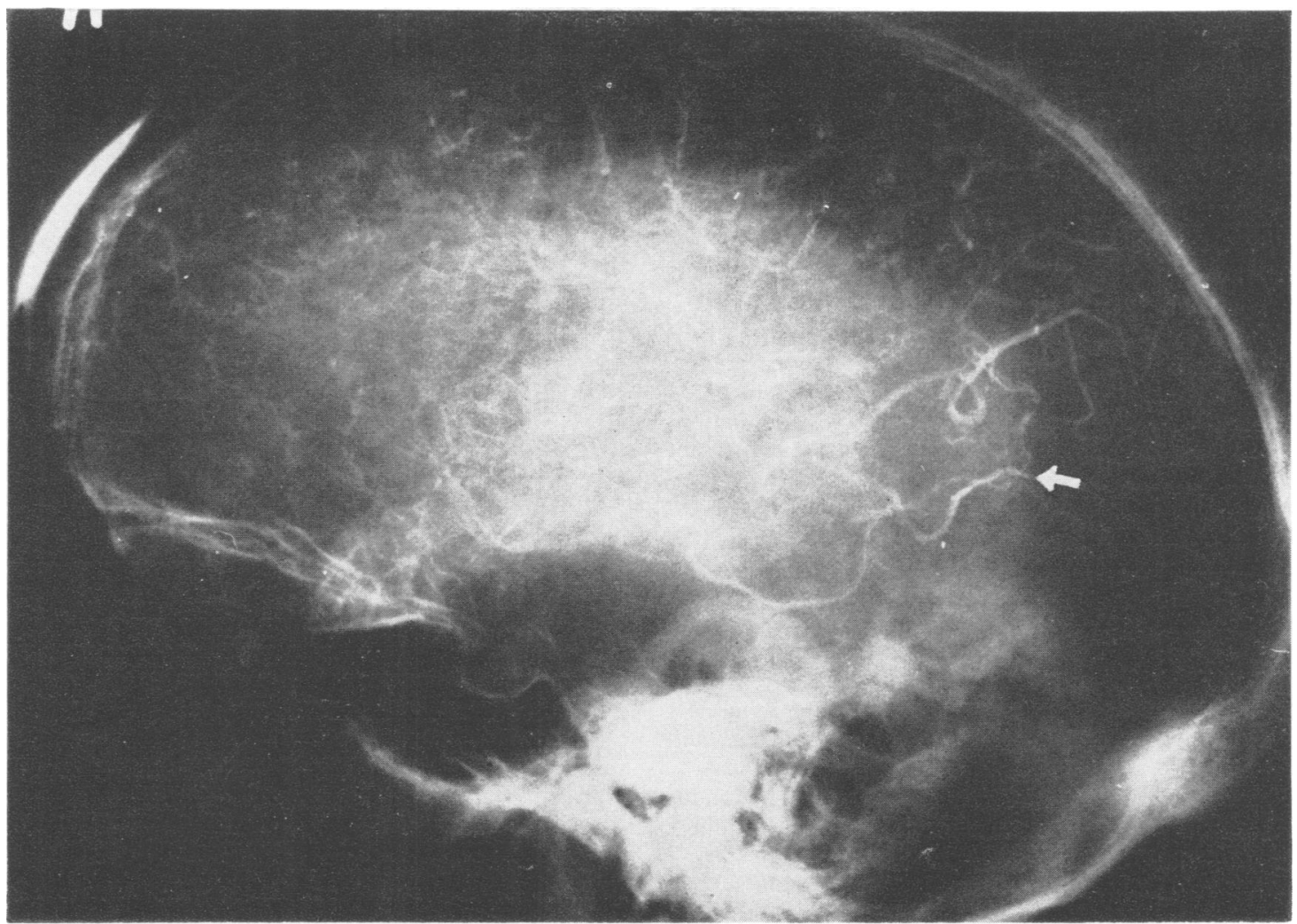

Fig. 2 Left carotid angiogram ( $\mathrm{Dr} B$. Kendall) three weeks after an episode of left sided amaurosis fugax, showing occlusion of a posterior branch of the middle cerebral artery (arrowed) (Patient FC).

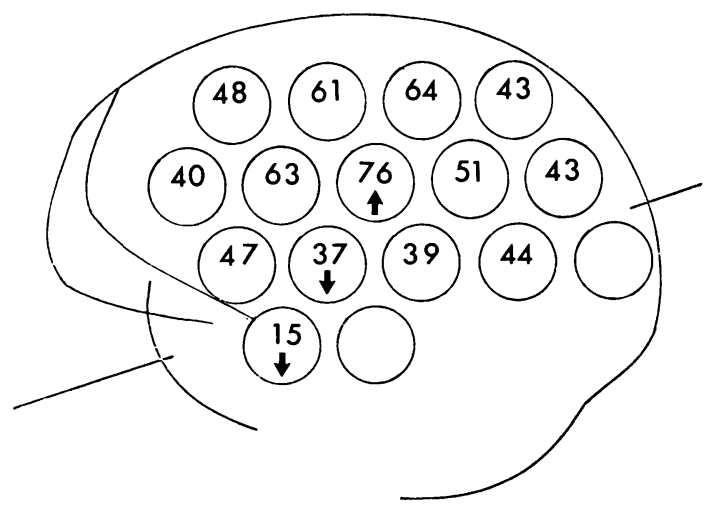

Fig. 3 Regional cerebral blood flow study 12 days after an episode of amaurosis fugax, showing the values for initial flow in 14 detectors in $\mathrm{ml} / 100 \mathrm{~g}$ tissue/minute. Those figures which were greater than 3.3 SD either side of control values are indicated by an arrow showing increased $(\uparrow)$ or reduced $(\downarrow)$ flow. There is an area of low flow in the left temporal region with a central hyperaemic area, findings compatible with cerebral infarction (Patient JC). brief. In one of their patients (their case 2) there had been no history of cerebral ischaemia, only a single attack of amaurosis fugax. The present study adds four further cases in which areas of low flow have been detected in the anterior or middle cerebral artery territory in patients with isolated amaurosis fugax. These few cerebral blood flow studies, therefore, strengthen the evidence for the occurrence of cerebral ischaemia in patients with retinal embolism.

Necropsy evidence suggests that cerebral infarction may occur in the absence of a history of cerebral ischaemia. In these cases the emboli are probably often of cardiac origin (Torvik and Jörgensen, 1966), whilst in the case of amaurosis fugax it seems more likely that they arise in the carotid artery (Stepyen et al., 1975).

The natural history of amaurosis fugax is not entirely clear but many fatients follow a benign course (Marshall and Meadows, 1968). The presence of coexistent cerebral symptoms is associated with a higher prevalence of arterial abnormality on angiography however (Wilson and Ross 
Russell, 1976). Whether associated evidence of silent cerebral involvement carries a prognostic significance remains to be seen. The question is an important one since the role of endarterectomy and anticoagulation in a condition which may have a benign course is problematical. If patients at risk for further cerebral involvement could be detected by EEG and non-invasive methods of measurement of cerebral blood flow, treatment might be applied more rationally.

\section{References}

Bauer, R. B., Meyer, J. S., Fields, W. S., Remington, R., MacDonald, M. C., and Callen, P. (1969). Joint study of extracranial arterial occlusion. Journal of the American Medical Association, 208, 509-518.

Dalal, P. M., Shah, P. M., and Aiyar, R. R. (1965). Arteriographic study of cerebral embolism. Lancet, 2, 358-361.

Evans, G. (1973). In Cerebral Vascular Diseases 8th Conference. Edited by F. McDowell and R. Brennan. Grune and Stratton: London.

Fisher, C. M. (1952). Transient monocular blindness associated with hemiplegia. Archives of Ophthalmology, 47, 167-203.

Fisher, C. M. (1959). Observations on the fundus oculi in transient monocular blindness. Neurology (Minneapolis), 9, 333-347.

Harrison, M. J. G., Meadows, J. C., Marshall, J., and Ross Russell, R. W. (1971). Effect of aspirin in amaurosis fugax. Lancet, 2, 743-744.

Hooshmand, H., Vines, F. S., Lee, H. M., and Grindal, A. (1974). Amaurosis fugax: diagnostic and therapeutic aspects. Stroke, 5, 643-647.

Marshall, J., and Meadows, S. (1968). The natural history of amaurosis fugax. Brain, 91, 419-434.
Rees, J. E., Bull, J. W. D., Ross Russell, R. W., Du Boulay, G. H., Marshall, J., and Symon, L. (1970). Regional cerebral blood flow in transient ischaemic attacks. Lancet, 2, 1210-1213.

Sandok, B. A., Trautman, J. C., Ramirez-Lassepas, M., Sundt, T. M., and Houser, O. W. (1974). Clinical angiographic correlations in amaurosis fugax. American Journal of Ophthalmology, 78, 137-142.

Shah, S., Bull, J. W. D., Du Boulay, G. H., Marshall, J., Ross Russell, R. W., and Symon, L. (1972). A comparison of rapid serial angiography and isotope clearance measurements in cerebrovascular disease. British Journal of Radiology, 45, 294-298.

Stepyen, D. H., Raulin, R. M., Stahler, C., and Gibbons, G. E. (1975). Amaurosis fugax. Stroke, 6, 493-496.

Torvik, A., and Jörgensen, L. (1966). Thrombotic and embolic occlusions of the carotid arteries in an autopsy series Part 2. Cerebral lesions and clinical course. Journal of the Neurological Sciences, 3, 410-432.

Van der Drift, J. H. A. (1972). The EEG in cerebrovascular disease. In Handbook of Clinical Neurology, Volume, 11, pp. 267-291. Edited by P. J. Vinken and G. W. Bruyn. North-Holland Publishing Co: Amsterdam.

Wilkinson, I. M. S., Bull, J. W. D., Du Boulay, G. H., Marshall, J., Ross Russell, R. W., and Symon, L. (1969). Regional blood flow in the normal cerebral hemisphere. Journal of Neurology, Neurosurgery, and Psychiatry, 32, 367-378.

Wilson, L. A., and Ross Russell, R. W. (1976). Amaurosis fugax and carotid artery disease: indications for angiography. British Medical Journal. In press.

Woolsey, R. M., and Hambrook, G. W. (1974). E.E.G. and angiographic findings in carotid artery transient ischaemic attacks (TIAs). Electroencephalography and Clinical Neurophysiology, 37, 436-437. 